\title{
Redundant colon as a cause of constipation
}

\author{
PEKKA BRUMMER, PENTTI SEPPÄLÄ, AND UNO WEGELIUS \\ From the Medical and Radiological Departments of the University Hospital, Turku, Finland
}

EDITORIAL SYNOPSIS The authors present evidence to show that a long colon is associated with constipation. In certain cases of intractable constipation associated with a long colon they recommend surgical treatment.

It is well known that megacolon may cause chronic constipation. On the other hand, the significance in this respect of another anomaly of the colon, namely, a long, or redundant, colon (dolichocolon), is not as clear. The excess length of a redundant colon is usually greatest in the distal colon, the most common variety being an enlarged sigmoid loop (Kantor, 1931). In contradistinction to the megacolon, dilatation of the lengthened portion and thickening of its wall are lacking in the redundant colon.

The concept of redundant colon was introduced into the literature by Kantor (1931). He found this anomaly in $343(18.5 \%)$ of 1,850 patients examined radiologically. The abdominal symptoms, which were more common in the patients with redundant colon than in his series in general, were constipation and distress caused by gas. Constipation was present in $66 \%$ of patients with redundant colon and in $46 \%$ of the whole series; the incidence of distress due to gas was 70 and $38 \%$ repectively. The incidence of redundant colon was approximately the same as the above in the necropsy series of Bryant (1924), among whose 242 examined subjects a redundant colon was encountered in $14 \%$. The somewhat higher incidence of $29 \%$ was seen in 100 patients with various types of colonic dysfunction reported by Bockus and Willard (1934).

There is no reference in the literature to the incidence of redundant colon in patients with constipation as compared with the incidence in persons without this symptom. However, on the basis of the figures reported by Kantor (1931) it can be calculated that $24 \%$ of patients with constipation and $13 \%$ of patients without constipation had a redundant colon.

For over 25 years, interest in the clinical importance of the redundant colon has been slight. Since the data presented above indicate that it is of some significance as one of the causes of chronic constipation, we have once more studied this question on the basis of a clinical series. For this purpose we have reviewed the records of 106 patients in whom a barium enema examination for chronic constipation was performed in this hospital between 1948 and 1960. For controls we used 53 patients in whom the same examination was carried out between 1959 and 1960 for reasons other than constipation. The most common reason was occult melaena or abdominal pain. None of the patients in the control series complained of constipation, not even as an accessory symptom.

In the constipation series there were 38 males and 68 females, and in the control series 13 males and 35 females. Distribution by age is given in Table $I$. As is seen in Table $I$, and as also could be expected,

\section{TABLE I}

AGE DISTRIBUTION

\begin{tabular}{ccc} 
Age (years) & Patients with Constipation & Controls \\
\hline $20-29$ & 22 & 9 \\
$40-59$ & 43 & 34 \\
$60-80$ & 41 & 10
\end{tabular}

the older age groups are somewhat larger in the constipation series. However, it is probable that this fact had no effect on the results.

All the $x$-ray plates in the constipation and control series were examined by the same person. He had no information on the exact case history of the patients with constipation, such as duration of the condition, but he was aware to which series the case belonged. In evaluating the length of the colon every effort was made to follow strictly the same criteria in all the cases and to avoid subjective judgments. The colons were subdivided into three groups according to length: normal, redundant, and borderline. In the last mentioned the colon appeared to be long, although the redundance could not definitely be regarded as exceeding normal limits. 
In cases in which the colon was considered to be clearly redundant the sigmoid colon regularly formed one or more large loops. In borderline cases there frequently was the same, though a smaller, pelvic loop. When carrying out this investigation we did not know the criteria applied by Kantor (1934) in the diagnosis of redundant colon. According to Kantor 'any case in which the enema-filled pelvic loop rises above a line joining the iliac crests is diagnosed redundant colon'. When we compare Kantor's criteria with those we used, we observe that all the cases in which the colon was regarded as redundant and some of the borderline cases fulfil Kantor's criteria.

In considering the case history, the duration of constipation was given primary attention. Originally the series was subdivided in this respect into four group as follows: 1, Patients with onset of constipation in childhood; 2 , patients with a history of constipation of over 10 years; 3, patients with a history of one to 10 years; and 4, patients with a history of less than one year. These groups consisted of $21,16,46$, and 23 patients, respectively. However, since in examining the series very little difference was observed between groups 1 and 2 and groups 3 and 4 , and since the groups so subdivided were too small, the cases are divided below into two groups only according to duration of the constipation, viz., patients with constipation of over 10 years' duration and of less than 10 years' duration.

The incidence of redundant colon in the present series is seen in Table II. It was clearly highest in patients with a history of constipation of over 10

TABLE II

INCIDENCE OF REDUNDANT COLON

\begin{tabular}{lcclc}
\begin{tabular}{l} 
State of $\begin{array}{l}\text { Colon } \\
\text { Patients with }\end{array}$ \\
\cline { 2 - 4 }
\end{tabular} & \multicolumn{2}{c}{ Constipation } & \\
\cline { 2 - 4 } & Duration of Constipation & Total & \\
\cline { 2 - 3 } & $>10$ Years & $<10$ Years & & \\
\hline Normal & $17(46 \%)$ & $45(65 \%)$ & $62(59 \%)$ & $47(89 \%)$ \\
Borderline & $3(8 \%)$ & $9(13 \%)$ & $12(11 \%)$ & $5(9 \%)$ \\
Redundant & $17(46 \%)$ & $15(22 \%)$ & $32(30 \%)$ & $1(2 \%)$
\end{tabular}

years. However, patients with a shorter history also showed a highly significant difference from the controls. In addition to redundant colon, the patients with constipation had a slightly higher incidence of coloptosis $(59 \%)$ than the controls $(36 \%)$. Likewise the emptying of the barium enema was more frequently retarded (42 and $14 \%$, respectively). On the other hand, spasticity and atony of the colon did not differ significantly, the former condition being present in 25 and $17 \%$ and the latter in 16 and $7 \%$.

\section{DISCUSSION}

According to the findings in the present series, redundant colon is clearly so much more common in patients with constipation that a causal connexion must exist between this anomaly and constipation. Since it does not appear probable that the first mentioned condition would be a result of the latter, it seems evident that in some cases of constipation the basic cause is a redundant colon, other common causes of chronic constipation, such as faulty diet, being contributory factors.

The opinion generally expressed in the literature is that even when a redundant colon is accompanied by chronic constipation the treatment of choice is purely conservative. However, we cannot but hold the opinion that in cases in which patients with redundant colon have suffered from severe constipation since childhood and cannot be satisfactorily managed with conservative treatment resection of the colon should be considered, especially in view of the improved results obtained today with surgery.

This work was assisted by a grant from the Sigrid Jusélius Foundation, Helsinki.

\section{REFERENCES}

Bockus, H. L., and Willard, J. H. (1934). Functional disorders of the colon. Penn. med. J., 37, 645-652.

Bryant, J. (1924). Observations upon the growth and length of the human intestine. Amer. J. med. Sci., 167, 499-520.

Kantor, J. L. (1931). Common anomalies of duodenum and colon: Their practical significance. J. Amer. med. Ass., 97, 1785-1790. (1934). Anomalies of the colon: Their roentgen diagnosis and clinical significance. Radiology, 23, 651-662. 